\title{
Modified Z-POEM technique to allow easier closure of the tunnel entry
}

\section{Introduction}

Zenker's diverticulum is an acquired herniation of the mucosa posteriorly through Killian's space. Treatment options are surgical, rigid endoscopic, or flexible endoscopic techniques. Flexible endoscopic treatment was first described in 1995 [1].

Cricopharyngeal mucomyotomy has a $91 \%$ success rate, with $11 \%$ adverse events (AEs) and $11 \%$ risk of recurrence [2].

Zenker's peroral endoscopic myotomy (Z-POEM) is a recently proposed technique using third space endoscopy to enable a complete division of the septum in order to decrease the risk of recurrence [3]. Complete closure of the tunnel is essential to avoid adverse events.

\section{Case description}

An 85-year-old woman presented with dysphagia due to Zenker's diverticulum ( Fig.1). It measured $2 \mathrm{~cm}$ on esophagram (\$Fig.2). She underwent a modified Z-POEM technique, as follows ( $\triangleright \mathbf{V i -}$ deo 1).

Submucosal injection with a combination of normal saline and methylene blue was followed by mucosal incision at the edge of the septum using a Hybrid $\mathrm{T}$ knife.

The incision (no longer than $1.5 \mathrm{~cm}$ ) leaned toward the diverticular side in order to allow an easier closure of the tunnel entry.

Dissection of the submucosal fibers was performed until the cricopharyngeal muscle was exposed. The submucosal fibers on both sides of the muscle were dissected (before entering the tunnel) using forced coagulation. Repeated injections were performed using the Erbe jet in order to avoid mucosal injury.

We avoided the temptation to enter the tunnel (particularly on the esophageal side) in order to avoid stretching and

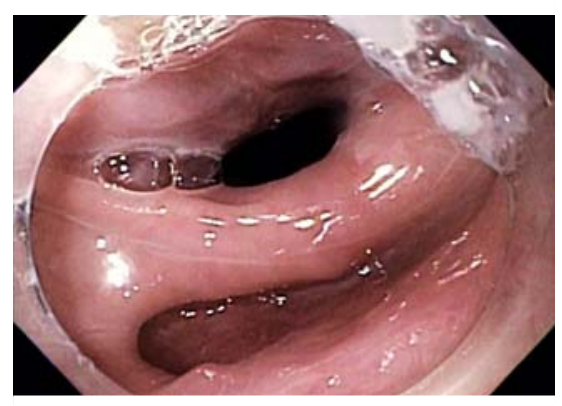

-Fig. 1 Zenker's diverticulum on endoscopy.

pushing the esophageal edge of the entry down toward the esophagus as this approach can make the tunnel closure more difficult. Instead, a "precut" was performed by starting to divide the cricopharyngeal muscle before entering the tunnel.

After partial myotomy, the endoscope entered the tunnel smoothly and the remaining cricopharyngeus fibers were divided completely ( $>$ Fig. 3 ). The tunnel entry ( Fig.4) was then easily closed using clips (> Fig. 5).

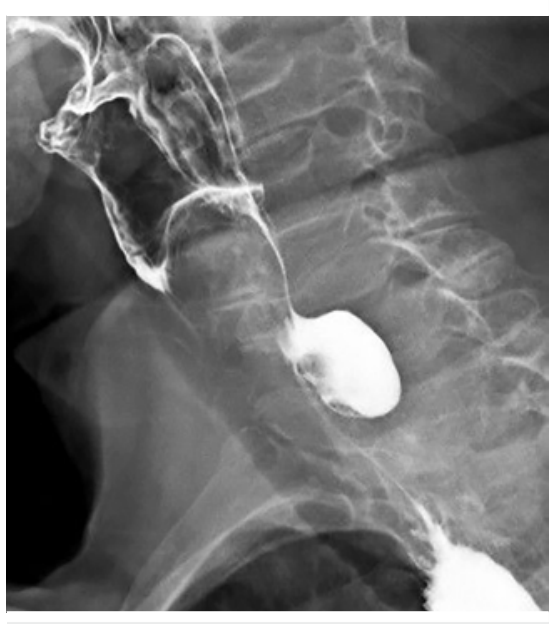

- Fig. 2 Zenker's diverticulum on esophagram.

There were no AEs. A water-soluble esophagogram performed the next day showed no leakage ( Fig.6). The patient's diet was advanced and she was discharged.

At a follow-up visit a week later her dysphagia resolved.

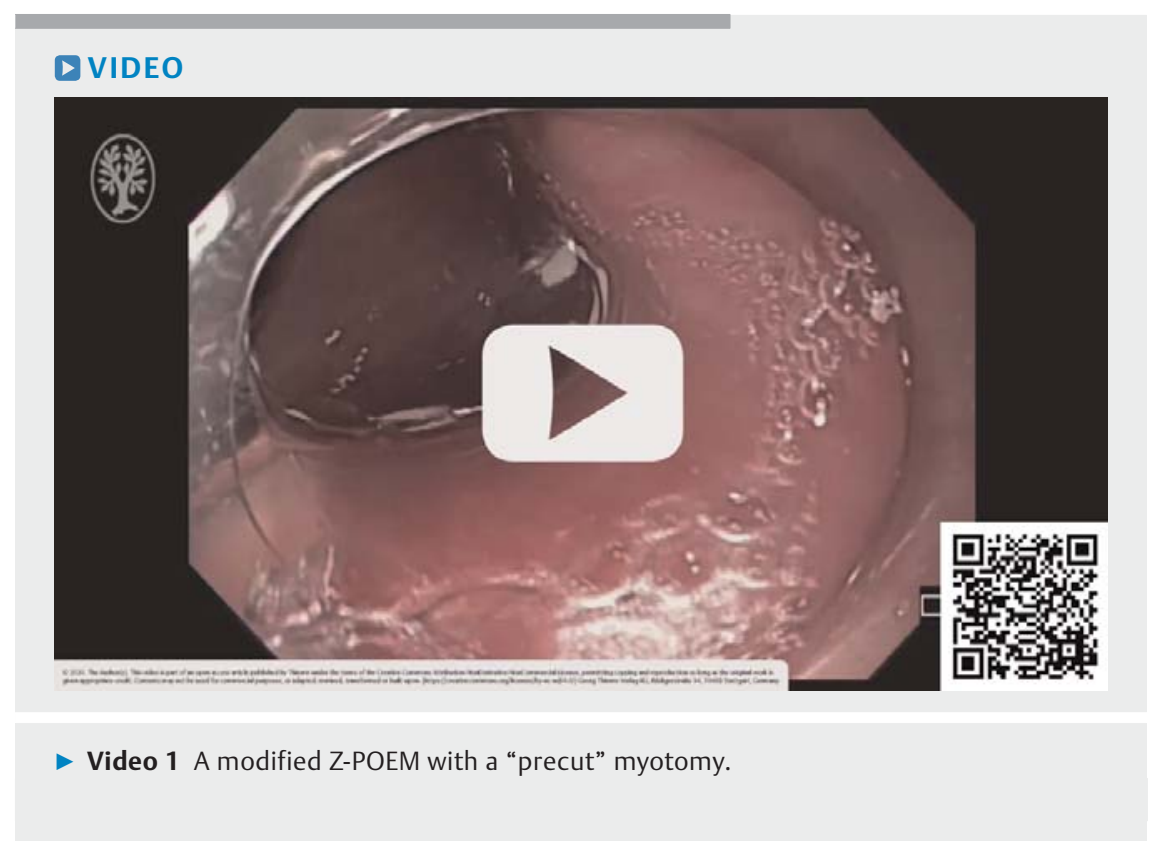




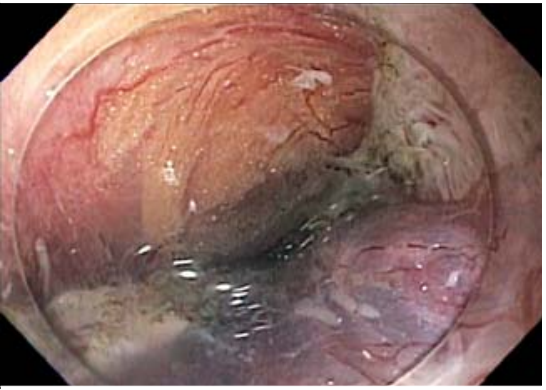

- Fig. 3 Endoscopic image of the tunnel after a complete myotomy.

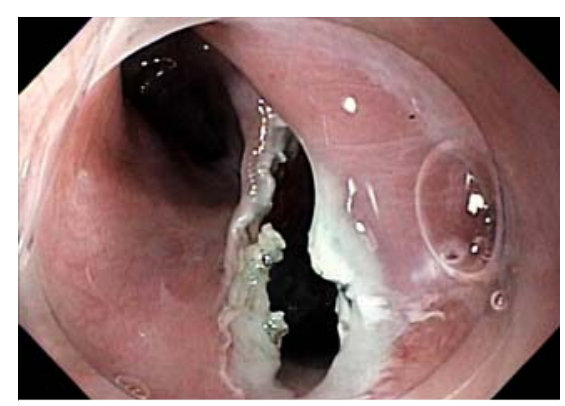

Dig. 4 Endoscopic image of the tunnel entry after completed myotomy.

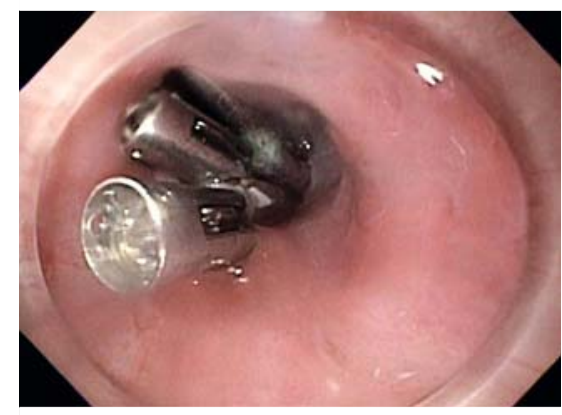

- Fig. 5 Endoscopic image of the tunnel entry after closure with clips.

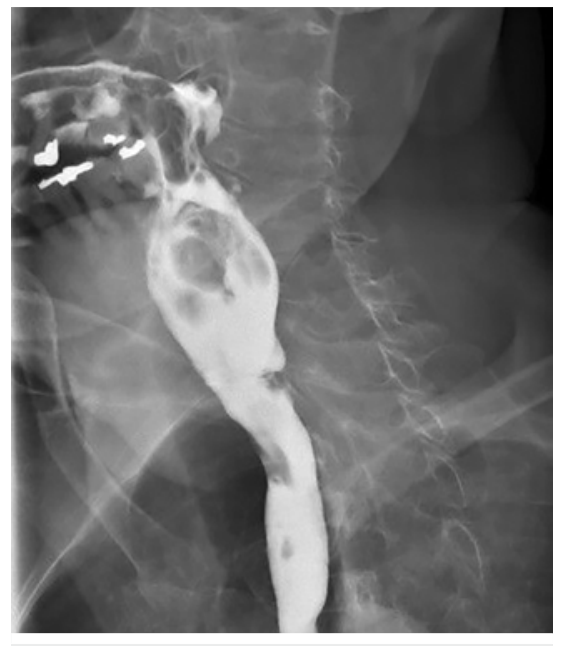

Fig. 6 Water-soluble esophagogram after Z-POEM.

\section{Conclusions}

While the Z-POEM technique is based on the premise that a complete cricopharyngeal muscle division decreases the risk of recurrence, a robust closure of the tunnel is essential to avoid complications.

Complete closure of the tunnel entry can be facilitated by limiting the length of the mucosal incision and leaning it toward the diverticular side. A "precut" of the cricopharyngeus muscle before entering the tunnel enables a smoother tunnel entry without stretching the edges. This might result in an easier closure of the tunnel.

\section{Competing interests}

The authors declare that they have no conflict of interest.

\section{The author}

\section{Michael Lajin}

Sharp Grossmont Hospital, La Mesa, California, United States

Corresponding author

\section{Michael Lajin}

8860 Center Drive Suite 330, La Mesa,

California 91942, United States

Fax: +1-619-460-5148

mlajin@yahoo.com

\section{References}

[1] Ishioka S, Sakai P, Maluf Filho F et al. Endoscopic incision of Zenker's diverticula. Endoscopy 1995; 27: 433-437

[2] Ishaq S, Hassan C, Antonello A et al. Flexible endoscopic treatment for Zenker's diverticulum: a systematic review and meta-analysis. Gastrointest Endosc 2016; 83: 1076 1089

[3] Yang J, Zeng X, Yuan X et al. An international study on the use of peroral endoscopic myotomy (POEM) in the management of esophageal diverticula: the first multicenter D-POEM experience. Endoscopy 2019; 51: 346-349

\section{Bibliography}

Endoscopy International Open 2021; 09: E423E424

DOI $10.1055 / \mathrm{a}-1337-2415$

ISSN 2364-3722

(c) 2021. The Author(s).

This is an open access article published by Thieme under the terms of the Creative Commons Attribution-NonDerivativeNonCommercial License, permitting copying and reproduction so long as the original work is given appropriate credit. Contents may not be used for commecial purposes, or adapted, remixed, transformed or built upon. (https:// creativecommons.org/licenses/by-nc-nd/4.0/)

Georg Thieme Verlag KG, Rüdigerstraße 14, 70469 Stuttgart, Germany

\section{(이 $\odot \odot$}

